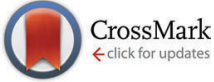

Cite this: New J. Chem., 2016, 40,5209

Received (in Montpellier, France) 18th December 2015 , Accepted 29th March 2016

DOI: 10.1039/c5nj03611a

www.rsc.org/njc

\title{
Energetic contribution to both acidity and conformational stability in peptide models $\uparrow$
}

\author{
Vladimir Kubyshkin,* Patrick Durkin and Nediljko Budisa*
}

\begin{abstract}
The acidity of $N$-acyl amino acids is dependent upon the rotameric state of the amide bond. In this work we systematically investigated the acidity difference of the rotamers $\left(\Delta \mathrm{p} K_{\mathrm{a}}\right)$ in the frames of various acetylated amino acids. Our results indicated a mutual interaction of two carbonyl groups of an attractive type. We observed conservative $\Delta \mathrm{p} K_{\mathrm{a}} \mathrm{s}$ for acyclic amino acids $\left(2.2-3.0 \mathrm{~kJ} \mathrm{~mol}^{-1}\right)$, whereas in the case of alicyclic amino acids, the experimental values revealed a strong dependency on the structural context (1.5-4.4 $\left.\mathrm{kJ} \mathrm{mol}^{-1}\right)$. In homologous amino acids $\left(\alpha-, \beta-, \gamma^{-}\right.$, etc.), the strength of the attraction decays in an exponential fashion. Furthermore, the interaction can accumulate through a chain of amide bonds in a cascade fashion, as demonstrated by an Ac-Pro-Pro dipeptide. As a result, we demonstrate that $\Delta \mathrm{p} K_{\mathrm{a}}$ is an experimental parameter to estimate increments in the carbonyl-carbonyl alignment, as determined by the amino acid or peptidyl context. This parameter is also important in understanding the roles of amino acids in both protein folding and translation in biological systems as well as their evolutionary appearance in the genetic code.
\end{abstract}

\section{Introduction}

There are a number of non-covalent interactions that govern the folding of polypeptides such as hydrogen bonds, electrostatic attraction (salt bridges) and repulsion, various aromatic stacking interactions $(\pi-\pi$, cation- $\pi$, aliphatic- $\pi$, aromatic-Pro or aromatic-Met), dipolar interactions and $n \rightarrow \pi^{*}$ donation. Some of these, like hydrogen bonding, are very well described in chemistry and biology as their distances and impact are easy to observe by conventional methods such as X-ray crystallography, NMR, CD, and IR. On the other hand, there are structural motifs, such as the polyproline II helix, where the driving forces behind this organization are more difficult to understand, rationalize and follow experimentally. The left-handed polyproline II (PPII) helix was initially described in $1956^{1}$ and later found to be a ubiquitous structure, not only in fibrillar structures like collagen, but also in many folded and unfolded proteins. ${ }^{2-4}$ Conversely, the right-handed polyproline I helix (PPI) only has limited biological relevance. ${ }^{5}$ Although proline has a high PPII propensity, this topology can also be generated in the absence of proline residues, such as in antifreeze glycoproteins. ${ }^{6}$

Clearly, PPII is an essential secondary structure of proteins that participates in major vital biological functions (transcription, signal transduction, ligand-receptor interplay, protein-protein

Biocatalysis Group, Institute of Chemistry, Technical University of Berlin, Müller-Breslau-Str., 10, 10623, Berlin, Germany.E-mail: kubyshkin@win.tu-berlin.de, nediljko.budisa@tu-berlin.de

$\dagger$ Electronic supplementary information (ESI) available. See DOI: 10.1039/ c5nj03611a interactions, etc.). ${ }^{7}$ Thus, the fundamental goal is to understand and (if possible) to quantify the nature and extent of the forces behind its stability. This is particularly relevant for the canonical secondary amino acid proline which has a comparable energy of the s-trans and s-cis peptide bonds, thereby exhibiting an equilibrium of both peptide bond isomers in solution (Scheme 1). ${ }^{8}$ Equally important is the amount of energy required for the stabilization of this structure, since entropy (at least to a certain extent) should oppose the formation of an ordered structure.

One possible rationalization for this stabilization is the $n \rightarrow \pi^{*}$ donation, a donative effect established between the oxygen lone pair of an upstream amide bond to the carbon atom of the downstream carbonyl. Since it represents a form of a nucleophilic attack, it should therefore be enhanced by certain dihedral angles that optimize the angle of donation (the Bürgi-Dunitz trajectory). An essential prerequisite for $n \rightarrow \pi^{*}$ donation is the s-trans conformation $\left(\omega=180^{\circ}\right)$ of the donating amide (Fig. 1).

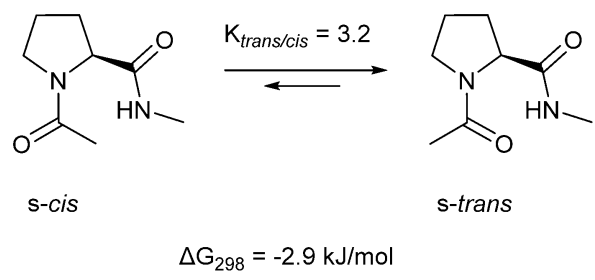

Scheme 1 trans/cis equilibrium in Ac-Pro-NHMe. The $\mathrm{s}$-trans rotamer is preferred over the s-cis by approx. $-3 \mathrm{~kJ} \mathrm{~mol}^{-1}$. 


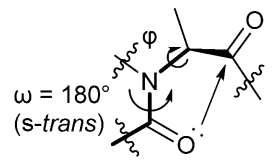

Fig. 1 The $n \rightarrow \pi^{*}$ interaction in a polypeptide chain.

Once established, the $n \rightarrow \pi^{*}$ donation results in (1) an energetic stabilization of particular secondary structural motifs, ${ }^{9}$ (2) the stabilization of the trans-amide bond over the cis-isomer, ${ }^{10}$ and (3) the partial pyramidalization of the carbonyl carbon atom. ${ }^{11}$ It has also been argued, however, that a classical dipole-dipole interaction might be mistaken as being an $n \rightarrow \pi^{*}$ interaction. $^{12}$ Recently, a crystal structure of the PPII helix demonstrated, in contrast, the existence of a certain degree of pyramidalization of proline carbonyl groups, which could originate from a specific donation. ${ }^{13}$ For a proline residue, indeed, the $n \rightarrow \pi^{*}$ interaction can play a significant role, since its $\phi$ angle $(-65 \pm 10)$ is naturally fixed around a value optimal for this donation $(-63 \pm 6) .{ }^{9}$ In proline-rich structures, such as polyproline or collagen, which lack other types of non-covalent interactions, the accumulation of the $n \rightarrow \pi^{*}$ donation through a peptide chain may give rise to a significant stabilizing effect due to entropic pre-organization. ${ }^{14}$

A critical question is whether the energetic contribution of this interaction can be of any significance in terms of a single residue. From a chemical standpoint, it appears to be doubtful that the amide oxygen can donate enough electron density to enable significant structural stabilization. An alternative explanation might be the dipole-dipole interaction established between the two carbonyl groups. Both effects, $n \rightarrow \pi^{*}$ and the dipole-dipole interactions, may potentially result in the relative stabilization of similar dihedral angles in a proline residue (in particular, the trans-amide bond), and from this standpoint they cannot be distinguished (Fig. 2).

Furthermore, by using proline analogues containing polar substituents (such as fluorine or hydroxyl groups), additional interacting dipoles will be present which are capable of participating in the overall interaction. Alternatively, in this case the conformational preferences can be obtained by the geometric
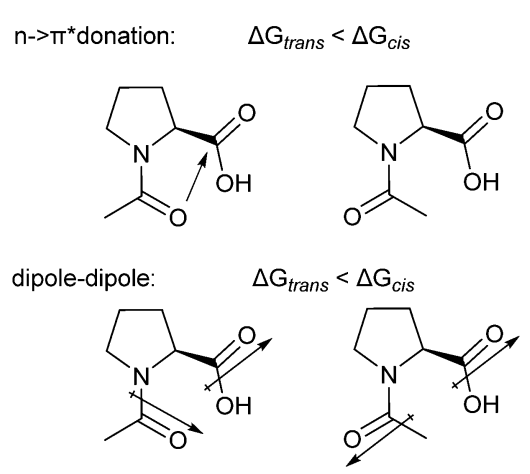

Fig. 2 Both $n \rightarrow \pi^{\star}$ donation and dipole-dipole interaction will result in relative stabilization of the $\mathrm{s}$-trans amide (left). Arbitrary orientation of the $\mathrm{C}$-terminal dipole is given for the plane projection here (see also Fig. 14). pre-organization of the trajectory between the interacting peptide bonds due to the changes in the pyrrolidine conformational states (exo/endo pucker equilibrium). As a result, the trans/cis equilibrium is known to experience dramatic variations. ${ }^{15}$

The final outcome of this mutual interaction of the polar groups must result in a change in the electronic state of the interacting groups, and hence their chemical reactivities. The latter conclusion is particularly interesting, since the ribosomal translation of proline is also known to be slow and may be as a result of the above mentioned interactions, seen as a donative effect. Furthermore, oligoproline segments in polypeptide sequences slow down the whole translation process, and can induce ribosome stalling, ${ }^{16}$ in particular when accommodated on the P-site. ${ }^{17}$ Since the C-terminal group in peptidyltRNA on the P-site should be attacked by an amino group in the course of a peptidyl transfer reaction on the ribosome (Fig. 3), the interactions that will reduce the electrophilicity of the carbonyl group may also slow down the rate of the reaction. Supporting this suggestion, we previously reported dramatic differences in the translation efficiency in living cells for $(4 R)$ - and $(4 S)$-fluoro- and hydroxyprolines. ${ }^{18}$

To determine a possible logical link between the chemical reactivity and the folding energy, we turned our attention to the acidity of the terminal carboxyl group in $N$-acetyl proline and the other amino acid residues. Indeed, it has been discovered in the mid-1970s that $N$-acylated proline and sarcosine (Sar) exhibit different acidities of their amide rotameric forms, where the s-trans rotamer is less acidic than s-cis (Fig. 4). ${ }^{19,20}$ $\mathrm{N}$-Acylated Pro and Sar were convenient subjects for the studies, since their rotameric populations are of comparable intensity in the NMR spectra, where sensitivity is a general problem. In the times when robust water suppression techniques were still absent, ${ }^{21}$ the $\mathrm{p} K_{\mathrm{a}}$ values for the rotameric states were determined by means of ${ }^{13} \mathrm{C},{ }^{15} \mathrm{~N}$ and ${ }^{17} \mathrm{O}$ NMR, delivering results with a certain degree of discrepancy. ${ }^{19,22,23}$

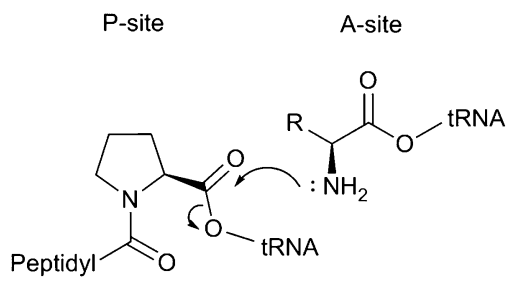

Fig. 3 Peptidyl transfer reaction with peptidyl-Pro on the P-site of the ribosome.
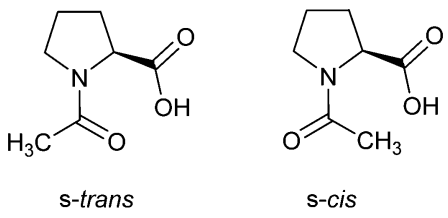

$\mathrm{pK}_{\mathrm{a}}$ (s-trans) $-\mathrm{pK}_{\mathrm{a}}(\mathrm{s}-c i s)=\Delta \mathrm{pK}_{\mathrm{a}}>0$

Fig. 4 Acidity difference characterized for $\mathrm{N}$-acetyl proline (Ac-Pro). 
These initial studies revealed, among others, that the difference in the acidity of the two rotamers $\left(\Delta \mathrm{p} K_{\mathrm{a}}\right)$ is defined by the mutual interaction of the amide and carboxyl groups. The origin of $\Delta \mathrm{p} K_{\mathrm{a}}$ therefore can be seen in the following way: if the $n \rightarrow \pi^{*}$ donation takes place in Ac-Pro, the electrophilicity of the terminal carbonyl group is reduced, but only in the case when the peptide bond is in the s-trans conformation. ${ }^{10 b, 24}$ From that, it follows that the resulting acidity of the s-trans rotamer should be then lower than in the s-cis $\left(\Delta \mathrm{p} K_{\mathrm{a}}>0\right)$. On the other hand, if the dipole-dipole interaction contributes to the stabilization of the s-trans rotameric form, the effect should be stronger when the terminal group is a carboxylic acid (a large dipole) than salt (a small dipole). Eventually the effect should result in a reduced acidity of the trans-rotamer $\left(\Delta \mathrm{p} K_{\mathrm{a}}>0\right)$. In a similar fashion to the conformational considerations, both interactions predict the same outcome for the acidity as well.

In this context, we set out to study the acidity differences in various $N$-acetylated amino acids in order to provide an experimental set of parameters for understanding the carbonylgroup alignment in terms of the energy of the interaction. Additionally, we also aimed to provide a solid experimental parameter that would make a logical link between the conformational energy and the chemical reactivity. However, the readers should be fully aware to draw their own conclusion from the present study concerning the molecular origins of the discussed energetic term.

\section{Experimental section}

\section{1. $\quad \mathrm{N}$-Acylation of the amino acids}

A typical procedure for the synthesis of $\mathbf{N}$-acetyl proline: L-Proline (2.26 g; $19.7 \mathrm{mmol}, 1$ equiv.) was stirred with anhydrous dichloromethane $(40 \mathrm{ml})$ and acetic anhydride $(1.85 \mathrm{ml}$; $19.6 \mathrm{mmol}, 1$ equiv.) until a clear solution was obtained (30 min). Dichloromethane was removed under reduced pressure and the residue was dissolved in water $(20 \mathrm{ml})$ and freeze-dried. Resulting solid contained approx. 1/10 of unreacted proline, therefore it was dissolved in water $(25 \mathrm{ml})$ and filtered through a short ionexchange column (Dowex ${ }^{\circledR}$ 50WX8, 50-100 mesh). Acidic fractions were collected and freeze-dried to give $2.79 \mathrm{~g}$ of $\mathrm{N}$-acetyl proline as white solid (91\% yield).

For analytical characterization of the substances 11, 12, 15, 16, 17, 18, 19 and 20 see the ESI. $\dagger$ For the already known compounds, 1, 2, 3, 7, and 22 spectral data are also given in the ESI. $\dagger$

\subsection{Determination of the carboxyl $\mathrm{p} K_{\mathrm{a}}$ in Ac-Xaa}

A typical procedure was as follows:

Ac-Xaa (5 mg) and potassium dihydrogenphosphate (5-6 mg) were dissolved in $10 \mathrm{ml}$ of water and titrated with potassium hydroxide and hydrochloric acid solutions to different $\mathrm{pH}$ values ranging from 7 to $1.12-15$ aliquots with $500 \mu \mathrm{l}$ volume were taken in NMR tubes, followed by the addition of $50 \mu \mathrm{l}$ TPS (sodium 3-(trimethylsilyl)propane-1-sulfonate) solution in deuterium oxide (0.1 $\mathrm{mg} \mathrm{ml}^{-1}$ ) to each tube for lock and referencing. Final concentration in the samples was: Ac-Xaa 2-4 mM, phosphate
7-8 $\mathrm{mM}$, and TPS $0.1 \mathrm{mM}$. ${ }^{1} \mathrm{H}$ NMR spectra were recorded at either 500 or $700 \mathrm{MHz}$ frequency in a Watergate W5 pulse sequence with the calibrated pulses. For $\mathrm{pH}<2$ pulses were re-calibrated for each sample due to the increased ionic strength of the solutions. TPS most upfield resonance was set to zero, except for the spectra of the most acidic samples $(\mathrm{pH} \leq 1.5)$, for which TPS resonances deviated due to the partial protonation of the sulfonic group. In that case we used any visible additive in the spectrum, for instance, methanol resonance at $3.349 \mathrm{ppm}$ for the referencing. Chemical shifts were read out and plotted against pH. In particular, acetyl $\mathrm{CH}_{3}$-group resonance was taken with three digits after the decimal in the chemical shift value. In this case the s-trans-chemical shift was higher than s-cis, with the only exception of Ac-MeAla. Chemical shift vs. pH curves were fitted according to either Boltzmann or Logistic fits (OriginPro 9.1), the fits were derivatized and the global maximum of the derivative curves was read as the $\mathrm{p} K_{\mathrm{a}}$ value. The derivative curves were checked to exhibit a symmetric shape.

In particular, using this procedure we determined the $\mathrm{p} K_{\mathrm{a}}$ values for Ac-Sar, Ac-Aze, and Ac-Pip. For fluorine containing Ac-Xaa also ${ }^{19} \mathrm{~F}\left\{{ }^{1} \mathrm{H}\right\}$ NMR spectra were recorded in inverse-gated decoupling experiments (no NOE enhancement).

In addition, for Ac-Pro we determined the $\mathrm{p} K_{\mathrm{a}}$ values under the following conditions:

Ac-Pro $\leq 0.5 \mathrm{mM} /$ citric buffer $100 \mathrm{mM}$

$\mathrm{p} K_{\mathrm{a}} \mathrm{s}-$ cis 2.79; s-trans 3.54

Ac-Pro $25 \mathrm{mM} /$ no buffer

$\mathrm{p} K_{\mathrm{a}} \mathrm{s}$-cis 2.79; s-trans 3.56

where it was seen that the $\mathrm{p} K_{\mathrm{a}}$ values (in particular, for the $\mathrm{s}$-trans form, which is more reliable in detection) are invariant to the offered conditions of the analyte or buffer concentrations.

For Ac-Xaa with the secondary amide (Ac-Gly, Ac-Val, Ac-Ile) we used higher concentrations of the analytes (25, 40 or $100 \mathrm{mM}$ ) in order to detect the minor rotameric form. For examples also see the ESI, $\dagger$ Section 4 .

\subsection{Equilibrium populations in acids and salts}

We found that a 140-170 $\mathrm{mM}$ solution of potassium hydrogen sulphate solution delivers $\mathrm{pH}$ values of 1.4-1.3, also, when some amount of Ac-Pro is present in solution. Therefore the acidic samples were prepared as follows. Ac-Xaa $(5 \mathrm{mg})$ and potassium hydrogen sulphate (10-12 $\mathrm{mg}$ ) were freeze-dried from deuterium oxide $(500 \mu \mathrm{l})$ and then dissolved in deuterium oxide $(525 \mu \mathrm{l})$, and this sample was then used for the measurements. The final concentration of Ac-Xaa was therefore 40-70 mM.

Salt samples were prepared as follows. Ac-Xaa $(10 \mathrm{mg})$ and potassium dihydrogenphosphate (10-12 mg) were dissolved in water $(1 \mathrm{ml})$ and titrated with potassium hydroxide solution to $\mathrm{pH}$ 6.9-7.1. An aliquot of this solution $(525 \mu \mathrm{l})$ was freeze-dried from deuterium oxide $(2 \times 500 \mu \mathrm{l})$ and taken into deuterium oxide $(525 \mu \mathrm{l})$ for the NMR measurements. Final phosphate concentration was therefore 70-80 mM, and Ac-Xaa concentration was $40-70 \mathrm{mM}$. Due to the slow amide rotation in salts, it turned out to be essential that some samples should be pre-equilibrated for at least one day standing at the room temperature prior the measurements. 
${ }^{1} \mathrm{H}$ NMR intensities were measured at $700 \mathrm{MHz}$ frequency in 90-pulse experiments in one scan in order to ensure complete pre-relaxation of the nuclei. In particular, the most characteristic $\alpha-\mathrm{CH}$ proton resonances characterized with the longest $\mathrm{T}_{1}$ relaxation times, and s-trans resonance relaxed slower than s-cis.

\subsection{Thermodynamic analysis}

Thermodynamic analysis was performed for the salt sample of Ac-Pro and Ac- $\beta$-homo-Pro, prepared as described above, and for the $N$-acetyl-2-methylpyrrolidine sample (see ESI $\dagger$ ). Equilibrium populations were measured by ${ }^{1} \mathrm{H}$ NMR at different temperatures. Temperature heating and cooling series were performed in the range of 295-355 K. The variable temperature unit was calibrated using standard methanol and glycerol sample measurements. ${ }^{25}$

For the final analysis we collected data points from several series and plotted them in coordinates $\Delta G_{\text {trans/cis }}$ versus $T$, rather than van't Hoff plot coordinates. Linear fit delivered the values of $\Delta H$ and $\Delta S$.

\subsection{Rotational barriers in different solvents}

The Ac-Pro-OK-18-crown-6 complex was prepared as follows: Ac-Pro was titrated with potassium hydroxide solution in the presence of a small amount of potassium dihydrogenphosphate additive to $\mathrm{pH} 7$. Followed by the addition of an equimolar amount of 18-crown-6 in acetonitrile-water the mixture was freeze-dried. The obtained solid contained Ac-Pro-OK/ 18-crown-6/ $\mathrm{H}_{2} \mathrm{O}$ in the $1: 1: 2$ ratio according to the ${ }^{1} \mathrm{H}$ NMR spectra.

Equilibrium constants for Ac-Pro-OMe and the Ac-Pro-OK. 18-crown- $6 \cdot 2 \mathrm{H}_{2} \mathrm{O}$ complex in perdeuterated solvents were measured by ${ }^{1} \mathrm{H}$ NMR at $298 \mathrm{~K}$ at $700 \mathrm{MHz}$ resonance frequency.

Rotational rates were measured in ${ }^{1} \mathrm{H} 2 \mathrm{D}$ cross relaxation experiments with gradients (NOESY-EXSY) with a typical mixing time of 1-2 s for exchange detection and $5 \mathrm{~ms}$ for referencing. Recycling delay was chosen to be $3-5 \cdot \mathrm{T}_{1}$ of the nucleus with slowest relaxation (usually, $\alpha-\mathrm{CH}$ of the s-trans rotamer). The latter was estimated in $1 \mathrm{D}$ inversion recovery experiments for each compound/solvent combination. Since relevant spectral windows varied with the solvents, the time domain was inset to give $2-4 \mathrm{~Hz}$ resolution in the direct and $10-30 \mathrm{~Hz}$ resolution in the indirect dimensions, respectively. In the processing step the indirect dimension was zero filled to reach the initial direct dimension resolution. 2D frequency domain spectra were phased, baseline corrected and integrated. Exchange rate matrices were calculated using EXSYCalc freeware (Mestrec). Activation energies were calculated using the Eyring equation. In addition to the exchange quantification, the EXSY spectra were interpreted as NOESY for the assignment of the rotameric forms.

\subsection{Equilibrium populations and $\mathrm{p} K_{\mathrm{a}}$ determination in Ac-Pro-Pro}

The Ac-Pro-Pro dipeptide was synthesized both on solid support and in solution as described in the ESI. $\dagger$ For the $\mathrm{p} K_{\mathrm{a}}$ measurements we followed $\mathrm{pH}$ dependencies of the most characteristic $\alpha-\mathrm{CH}$ resonances. Since the spectra contained eight such resonances
( 2 proline residues $\times 4$ rotameric forms) in very different intensities close to the water signal, and some of them overlapped, the measurements of all four $\mathrm{p} K_{\mathrm{a}}$ values were conducted in a series of $25{ }^{1} \mathrm{H}\left\{{ }^{13} \mathrm{C}\right\}$ HSQC spectra (cnst $150 \mathrm{~Hz}$, recycling delay 2 s) assisted by ${ }^{1} \mathrm{H}$ Watergate W5 and ${ }^{13} \mathrm{C}\left\{{ }^{1} \mathrm{H}\right\}$ dept45 experiments on samples with $\mathrm{pH}$ between 1 and 7 . The spectral windows were zoomed to the $\alpha-\mathrm{CH}$ region in both dimensions. The sample concentrations were: $100 \mathrm{mM}$ Ac-Pro-Pro and $14 \mathrm{mM}$ phosphate. Partial overlap of the signals was observed in ${ }^{1} \mathrm{H}$ and ${ }^{13} \mathrm{C}$ spectra, but simultaneous overlap in both dimensions was seldom. The titration curves and the $\mathrm{p} K_{\mathrm{a}}$ value read out were performed as described above for Ac-Xaa (also, see ESI $\dagger$ ).

For the ${ }^{1} \mathrm{H}$ NMR measurements of the equilibrium populations the acidic and salt samples in deuterium oxide were prepared as described for Ac-Xaa. The samples contained $75 \mathrm{mM}$ Ac-Pro-Pro and $140 \mathrm{mM}$ potassium hydrogen sulphate or $140 \mathrm{mM}$ potassium phosphate buffer for acid and salt respectively. ${ }^{1} \mathrm{H}$ NMR spectra were measured at $700 \mathrm{MHz}$ resonance frequency as described for Ac-Xaa. Quantified ${ }^{13} \mathrm{C}\left\{{ }^{1} \mathrm{H}\right\}$ spectra were acquired in samples containing 250 and $350 \mathrm{mM}$ Ac-Pro-Pro for the acid and salt respectively. The spectra were recorded in a 90-pulse inverse gated ${ }^{1} \mathrm{H}$ decoupled pulse sequence at $126 \mathrm{MHz}$ resonance frequency. Recycling delay was $60-80 \mathrm{~s}$ to ensure complete relaxation. 512-768 transients were enough to collect spectra with all four rotamers visible. It is important to note that the $\alpha-\mathrm{CH}$ intensity ratios obtained in quantified ${ }^{13} \mathrm{C}\left\{{ }^{1} \mathrm{H}\right\}$ NMR spectra were in good agreement (within $\pm 1 \%$ accuracy) with those obtained in ${ }^{13} \mathrm{C}\left\{{ }^{1} \mathrm{H}\right\}$ dept45 spectra with a routine setup (recycling delay $2 \mathrm{~s}$, cnst $150 \mathrm{~Hz}$ ). This observation justifies our approach of the $\mathrm{p} K_{\mathrm{a}}$ measurements conducted by HSQC, where the averaged populations of salt/acid upon the $\mathrm{p} K_{\mathrm{a}}$ transitions should deliver correct average of the chemical shifts according to their molar ratios. ${ }^{22}$

\section{Results and discussion}

\subsection{N-terminal amide cis/trans rotameric ratio as a function of the C-terminal group}

It has been previously demonstrated that the trans-content in $N$-acyl proline derivatives is dependent on the nature of the C-terminal group. Generally, $K_{\text {trans/cis }}$ is higher in the case of the terminal ester compared to the amide due to the differences in the enthalpic term. ${ }^{26}$ Further evaluation (Table 1) demonstrates that the preferences towards the s-trans conformation gradually decrease in the row $\mathrm{X}=\mathrm{OMe}>\mathrm{OH}>\mathrm{NHMe}>\mathrm{O}^{-}$, i.e. with the decrease in the carbonyl electrophilicity (the decrease in the $\mathrm{C}=\mathrm{O}$ dipole). The same occurs in the case when two C-terminal groups are integrated in the frame of one molecule.

In particular, for racemic $N$-acetyl-pyrrolidine-2,5-dicarboxylic acid mono methyl ester (Ac-(MeO)Pdc) the $K_{\text {trans } / c i s}$ values were predicted from the proline data as $K_{\text {trans } / \text { cis }}\left(\mathrm{Ac}-\mathrm{Pro}-\mathrm{OH} / \mathrm{O}^{-}\right) /$ $K_{\text {trans/cis }}($ Ac-Pro-OMe) values are in good agreement with the experimental values (Fig. 5; see also Fig. S61, ESI $\dagger$ for comparison in the entire $\mathrm{pH}$ range).

In the terminal case when the C-terminal group is a carboxylate, the effective charge on the carbonyl carbon is close to zero (Fig. 6). 
Table 1 Energetic terms of the amide equilibrium for Ac-Pro- $X$

\begin{tabular}{llllc}
\hline Ac-Pro-X & $K_{\text {trans/cis }}{ }^{a}$ & $\Delta G_{298}, \mathrm{~kJ} \mathrm{~mol}^{-1}$ & $\Delta H, \mathrm{~kJ} \mathrm{~mol}^{-1}$ & $\Delta S, \mathrm{~J} \mathrm{~mol}^{-1} \mathrm{~K}^{-1}$ \\
\hline $\mathrm{X}=\mathrm{OMe}^{27}$ & 4.8 & $-3.9 \pm 0.1$ & $-5.04 \pm 0.05$ & $-3.82 \pm 0.16$ \\
$\mathrm{X}=\mathrm{OH}$ & 3.8 & $-3.3 \pm 0.1$ & - & - \\
$\mathrm{X}=\mathrm{NHMe}^{8}$ & 3.2 & $-2.9 \pm 0.1$ & $-3.97 \pm 0.04$ & $-3.64 \pm 0.08$ \\
$\mathrm{X}=\mathrm{O}^{-}$ & 0.81 & $+0.5 \pm 0.2$ & $-1.17 \pm 0.10$ & $-5.24 \pm 0.30$
\end{tabular}

${ }^{a}$ In aqueous medium at $298 \mathrm{~K} .{ }^{b}$ The cis-to-trans rotation rate at $340 \mathrm{~K} .{ }^{c}$ The value is the largest because acidic medium catalyzes rotation at high temperature due to partial amide protonation.

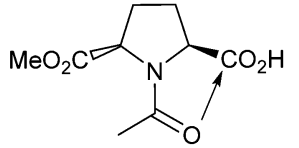

s-trans

$\mathrm{K}_{\text {trans/cis }}$

\begin{tabular}{|c|c|}
\hline at $\mathrm{pH} 1.5$ (acid) & 0.81 \\
\hline at $\mathrm{pH} 7$ (salt) & 0.18 \\
\hline
\end{tabular}

Fig. 5 In $\mathrm{N}$-acetyl-rac-(trans-)pyrrolidine-2,5-carboxylic acid mono methyl ester, Ac-(MeO)Pdc, two carboxylates compete for the donation from the amide carbonyl group. The resulting trans/cis equilibrium constant can be predicted from the data on proline.

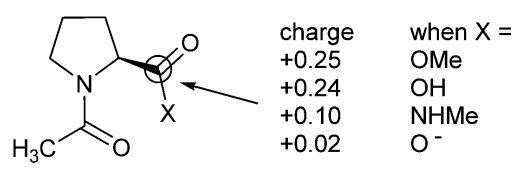

Fig. 6 Effective charge on the C-terminal carbon atom as dependent from the nature of the $\mathrm{C}$-terminal group. Simulated in MarvinSketch 15.4.27 (ChemAxon Ltd).

Therefore it can be expected that in the salts both $n \rightarrow \pi^{*}$ and the dipole-dipole interactions are substantially attenuated, and the trans/cis equilibrium is defined by the steric effects.
Subtraction of the $\Delta G_{\text {trans/cis }}$ values yields the energetic term $\Delta \Delta G$ which accounts for the effect of the peptide bond alignment due to the $n \rightarrow \pi^{*}$ and dipole-dipole interactions (eqn (1)). Instrumentally this value was experimentally determined by NMR in two different ways as described in the next section.

$$
\Delta \Delta G=\Delta G_{\text {trans } / \text { cis }}(\text { acid })-\Delta G_{\text {trans } / c i s}(\text { salt })
$$

\section{2. $\mathrm{p} K_{\mathrm{a}}$ and rotameric populations in Ac-Xaa}

The experimental approach is illustrated in Fig. 7. Because the acid-salt transition is fast on the NMR time scale, the mixture of the two ionization states provides an averaged chemical shift value, whereas the slow amide rotation enables one to observe the two rotamers separately (Fig. 7A). While going from basic to acidic $\mathrm{pH}$ values, the chemical shifts exhibit characteristic sigmoidal transitions (Fig. 7B), which is also accompanied by the change in the rotameric populations (Fig. 7C). The difference in the $\mathrm{p} K_{\mathrm{a}}$ exhibited by the two rotamers $\left(\Delta \mathrm{p} K_{\mathrm{a}}\right)$ corresponds to the free energy difference $\Delta \Delta G=\Delta G^{\circ}(\mathrm{A})-\Delta G^{\circ}(\mathrm{B})-\Delta G^{\circ}(\mathrm{C})+$ $\Delta G^{\circ}(\mathrm{D})$, which can also be calculated from the equilibrium populations according to eqn (2).

$$
\Delta \Delta G=-2.30 \cdot R T \Delta \mathrm{p} K_{\mathrm{a}}=-R T \ln \frac{K_{\text {trans } / \text { cis }}(\mathrm{acid})}{K_{\text {trans } / \text { cis }}(\mathrm{salt})}
$$

A<smiles>CC(=O)N1CCCC1C(=O)O</smiles>
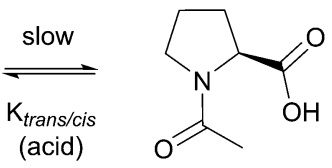

A fast $\| \begin{gathered}\mathrm{pK}_{\mathrm{a}} \\ \text { (s-trans) }\end{gathered}$<smiles>CC(=O)N1CCC[C@H]1C(=O)[O-]</smiles>

C

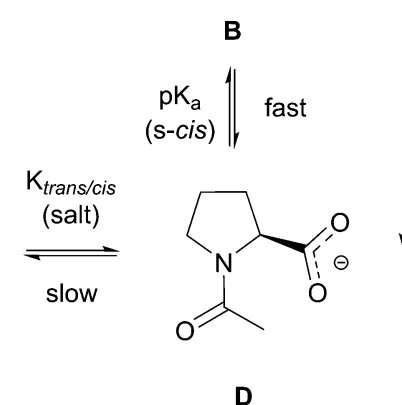

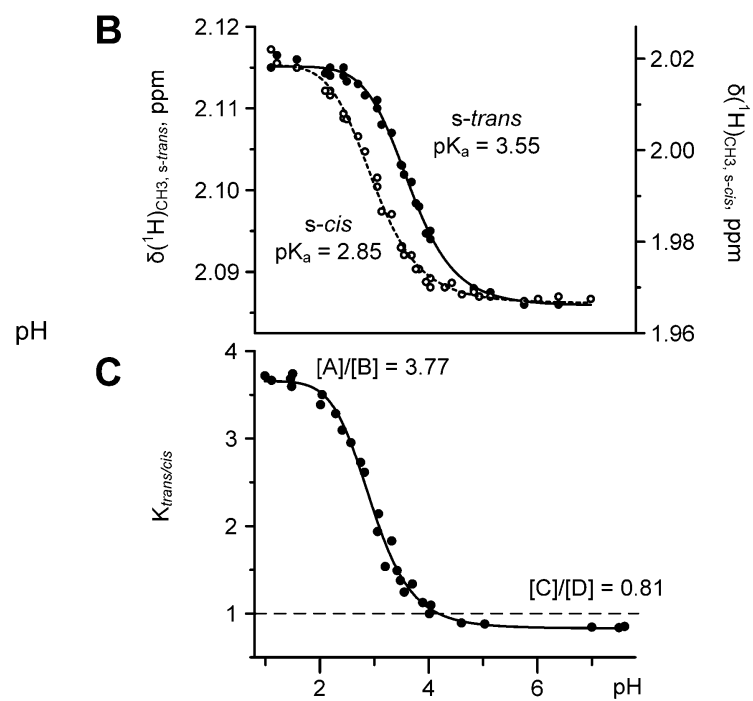

Fig. 7 (A) Equilibrium forms of Ac-Pro in aqueous medium and their interconversions; (B) pH dependence of the ${ }^{1} \mathrm{H} N M R$ chemical shifts ( $\mathrm{CH}$-groups) of the two amide rotamers of Ac-Pro. This plot is equivalent to $\mathrm{pH}$ titration curves; (C) $\mathrm{pH}$ dependence of the trans/cis equilibrium in Ac-Pro as determined by ${ }^{1} \mathrm{H}$ NMR spectra integration $\left(\delta-\mathrm{CH}_{2}\right.$ fragment). Observations are made at $298 \mathrm{~K}$. 
Since $\Delta \Delta G$ and $\Delta \mathrm{p} K_{\mathrm{a}}$ values are equivalent, we can also convert equilibrium constants to the $\Delta \mathrm{p} K_{\mathrm{a}}{ }^{*}$ values expressed according to eqn (3).

$$
\Delta \mathrm{p} K_{\mathrm{a}}^{*}=\log _{10} \frac{K_{\text {trans } / \text { cis }}(\text { acid })}{K_{\text {trans } / \text { cis }}(\text { salt })}
$$

Following these considerations, we determined the experimental $\mathrm{p} K_{\mathrm{a}}$ and $\Delta \mathrm{p} K_{\mathrm{a}}{ }^{*}$ parameters for 19 different $N$-acetyl amino acids with different structures (Fig. 8). In Table 2 we summarize the obtained values. The $\Delta \mathrm{p} K_{\mathrm{a}}$ and $\Delta \mathrm{p} K_{\mathrm{a}}{ }^{*}$ values found were in close agreement, providing a good mutual control. Doubtless, an important observation is that $\Delta \mathrm{p} K_{\mathrm{a}}$ exhibited positive values (the s-trans rotamer is less acidic) in all studied cases. In addition, the $\Delta \mathrm{p} K_{\mathrm{a}}$ and $\Delta \mathrm{p} K_{\mathrm{a}}{ }^{*}$ values for the Pdc derivative were in full agreement with the proline data.

Further careful inspection of our experimental data reveals several important observations. Firstly, comparison of the acidity values of the s-cis forms and the textbook acidities of the corresponding free amino acids (Pro, Gly, Ala, Phe, Val, Ile)

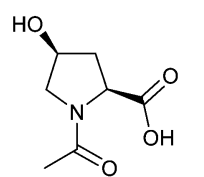

Ac-(4S)-Hyp

$\Delta \mathrm{pKa}=0.43$<smiles>CC(=O)N1C[C@H](F)C[C@H]1C(=O)O</smiles>

Ac-(4S)-FIp

$\Delta \mathrm{pKa}=0.52$

Ac-Pip

$\Delta \mathrm{pKa}=0.26$

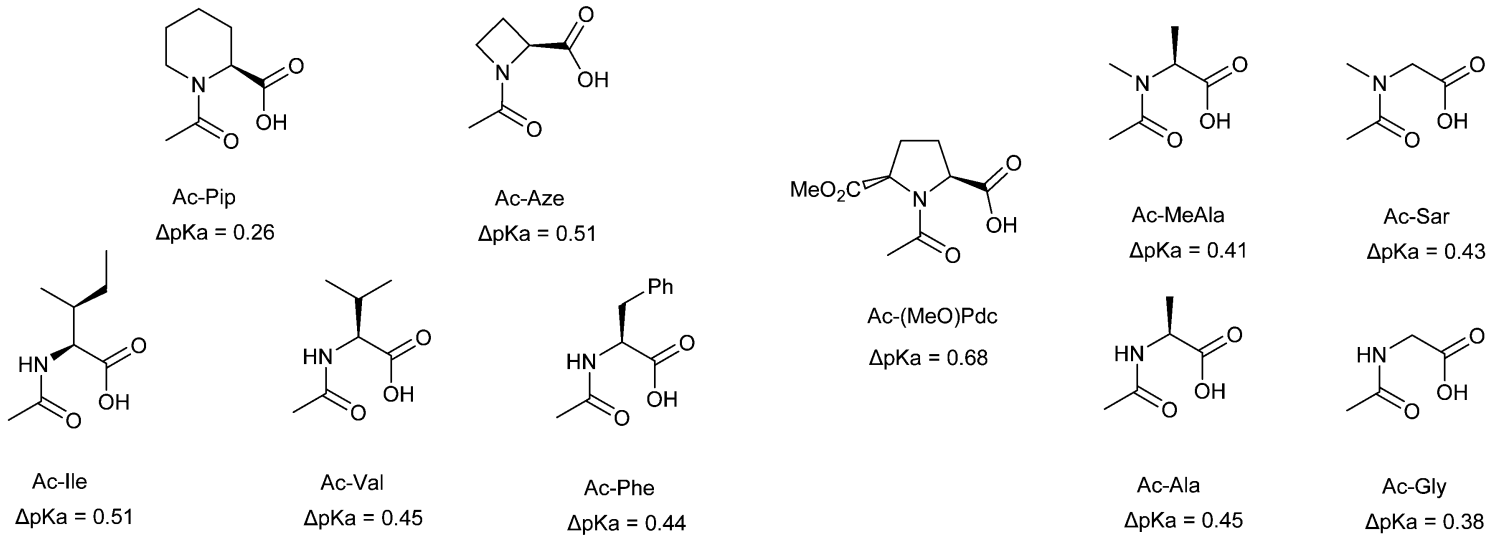<smiles>CC(=O)N1CC(F)(F)CC1C(=O)O</smiles>

Ac- $\mathrm{F}_{2}$ Pro

$\triangle \mathrm{pKa}=0.59$<smiles>CC(=O)N1C[C@H](C)CC1C(=O)O</smiles><smiles>CC(=O)N1CC(C(F)(F)F)CC1C(=O)O</smiles>

Ac-(4S)-TfmPro

$\Delta \mathrm{pKa}=0.64$<smiles>CC(=O)N1CCCC1C(=O)O</smiles>

Ac-Pro

$\Delta \mathrm{pKa}=0.70$<smiles>CC(=O)N1CC(C)CC1C(=O)O</smiles>

Ac-(4S)-Mep

$\Delta \mathrm{pKa}=0.75$<smiles>CC(=O)N1C[C@H](O)CC1C(=O)O</smiles>

Ac-(4R)-Hyp

$\Delta \mathrm{pKa}=0.76$

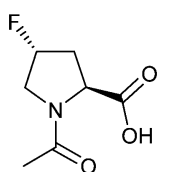

Ac-(4R)-Flp

$\Delta \mathrm{pKa}=0.82$

Fig. 8 The series of examined $N$-acetyl amino acids with the designated experimentally determined $\Delta \mathrm{p} K_{\mathrm{a}}=\mathrm{p} K_{\mathrm{a}}\left(\mathrm{s}\right.$-trans) $-\mathrm{p} K_{\mathrm{a}}(\mathrm{s}-\mathrm{cis}) \mathrm{values}$.

Table $2 \mathrm{p} K_{\mathrm{a}}$ and amide equilibrium constants determined for the examined $\mathrm{N}$-acetylated amino acids at $298 \mathrm{~K}$

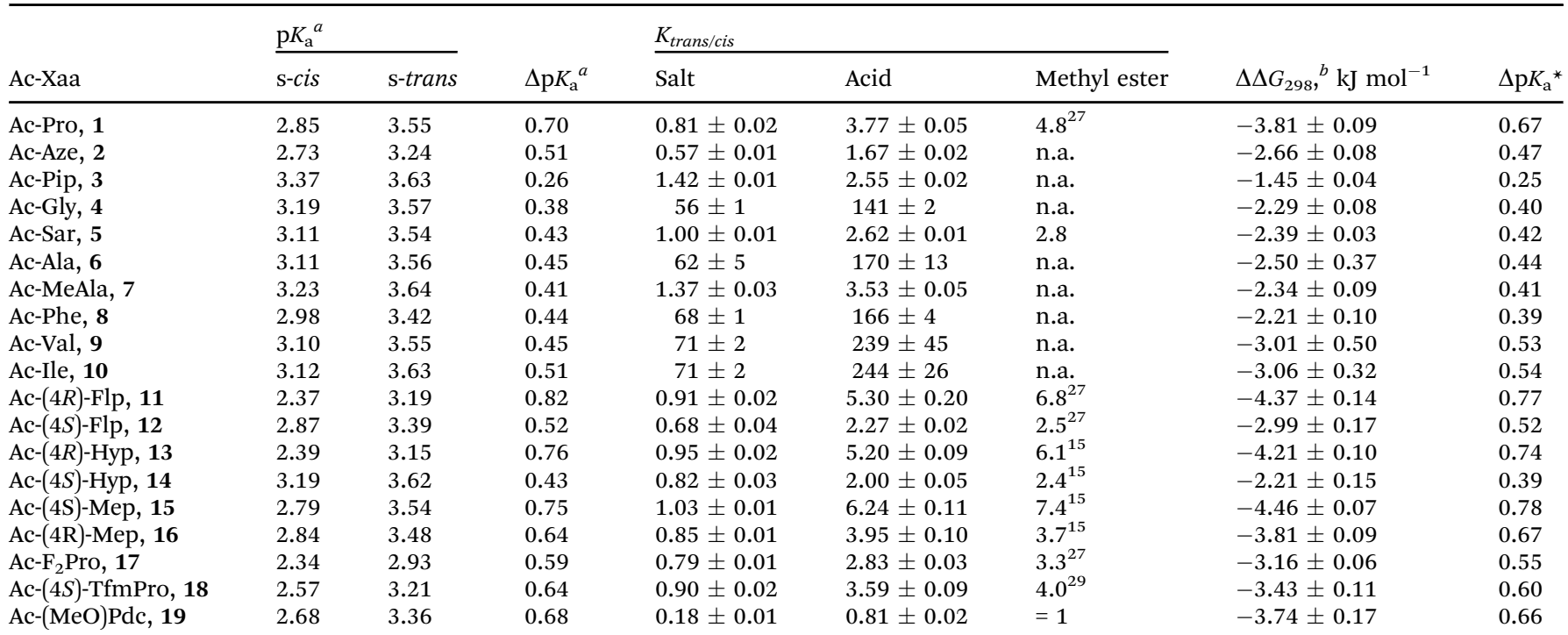

${ }^{a}$ The error of $\mathrm{p} K_{\mathrm{a}}$ and $\Delta \mathrm{p} K_{\mathrm{a}}$ determination is $\leq 0.05 .{ }^{b}$ Calculated from the equilibrium populations according to eqn (1). 

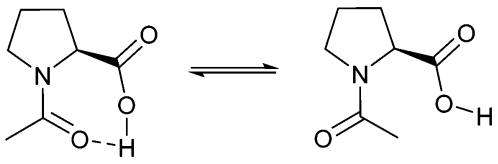

Scheme 2 Hydrogen bond that stabilizes the protonated carboxylate in the s-trans conformation in non-polar media.

reveals a conservative acidity reduction of 0.8-0.9 units. Considered mechanistically, this is the result of the absence of the compensating ammonium charge in the $N$-acetylated amino acids. At the same time, $\Delta \mathrm{p} K_{\mathrm{a}}$ appears to be a function of the amino acid context.

Secondly, the value of $\Delta \mathrm{p} K_{\mathrm{a}}$ increases when going from unsubstituted residues (Gly and Sar, $\Delta \mathrm{p} K_{\mathrm{a}} 0.4$ ) to $\beta$-branched amino acids (Val and Ile, $\Delta \mathrm{p} K_{\mathrm{a}} 0.5$ ), where the bulky sidechain substituent may reinforce a more stable alignment of the carbonyl-groups. The value was significantly higher for proline $\left(\Delta \mathrm{p} K_{\mathrm{a}} 0.7\right)$, whereas its homologs azetidine-2-carboxylic acid (Aze 0.5) and pipecolic acid (Pip 0.25) exhibit lower $\Delta \mathrm{p} K_{\mathrm{a}}$ values. ${ }^{28}$ Next, the incorporation of substituents at position 4 of the proline ring afforded significant changes in $\Delta \mathrm{p} K_{\mathrm{a}}$ in the range of about 0.4 units.

In the two cases of ( $4 R$ )-Flp and ( $4 R)$-Hyp, higher $\Delta \mathrm{p} K_{\mathrm{a}}$ values are accompanied by the higher absolute acidity of both rotameric forms. In contrast, $(4 S)$-TfmPro and $\mathrm{F}_{2}$ Pro higher acidity values do not correlate with the increments in $\Delta \mathrm{p} K_{\mathrm{a}}$. This is indeed an important observation which contradicts the presence of the hydrogen bond between the carboxyl group and amide carbonyl group that might potentially stabilize the s-trans conformation (Scheme 2). Previously in the 1980s, it was reported that "a hydrogen bond between the terminal carboxyl group and the preceding amide carbonyl could be ruled out in polar media ${ }^{, 19 b}$ based on considerations of heteronuclear NMR. The fact that $\Delta \mathrm{p} K_{\mathrm{a}}$ does not correlate with the absolute acidity further strengthens such conclusions (see also the Pdc example). It further indicates that the effect of donation is not driven by the carboxyl-group electrophilicity alone, but it also clearly accounts for conformational preferences of the proline ring.

Noteworthily, (4S)-Hyp, which exhibited low $\Delta \mathrm{p} K_{\mathrm{a}}$ (as well as $K_{\text {trans/cis }}$ ), turned out to also be the least acidic. It could be that the hydrogen bond between the carboxyl-group and 4-OH group shifts the absolute acidity without affecting $\Delta \mathrm{p} K_{\mathrm{a}}$. Another explanation would be the presence of the $n \rightarrow \pi^{*}$ donation between these two functionalities. The latter has been reported in simulations in the gas phase. ${ }^{30}$ The first explanation seems to be more plausible, since the absolute acidity shift was not observed in (4S)-Flp. Indeed, the hydroxyl group may engage in specific hydrogen bonding with the carboxyl group, since a hydroxyl group is more donative than water, which is not the case for an aliphatic fluorine substituent. ${ }^{31}$

\section{3. $\Delta \mathrm{p} K_{\mathrm{a}}$ and the rotameric populations in esters}

Subsequently, we compared the $\Delta \mathrm{p} K_{\mathrm{a}}$ values found with the already known trans/cis preferences in the methyl esters of the $\mathrm{N}$-acetylated prolines bearing substitutions in position 4
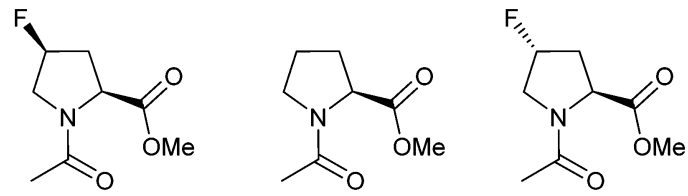

$$
-2.3 \mathrm{~kJ} / \mathrm{mol}
$$

Ac-(4S)-FIp-OMe

$\Delta \mathrm{G}_{\text {trans } / \mathrm{cis}}=$

$-3.9 \mathrm{~kJ} / \mathrm{mol}$

$-4.7 \mathrm{~kJ} / \mathrm{mol}$

Ac-Pro-OMe

Ac-(4R)-FIp-OMe

Fig. 9 Dominance of the s-trans rotamer varies in 4-substituted prolines. $^{15,27}$

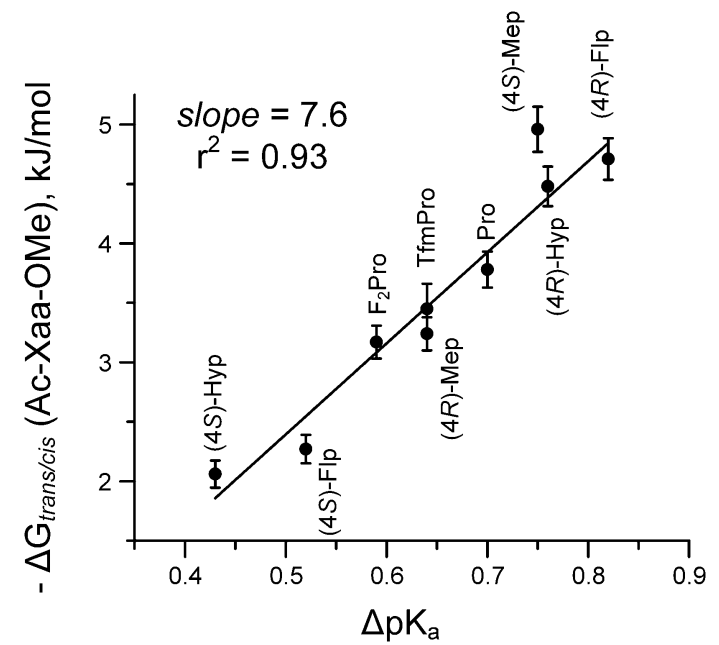

Fig. 10 Linear free energy correlation between the Ac-Xaa rotameric acidity differences and Ac-Xaa-OMe equilibrium rotameric populations in 4-substituted proline analogues.

of the pyrrolidine ring (Fig. 9). We found that the $\Delta \mathrm{p} K_{\mathrm{a}}$ aligns with their ester population preferences with a decent agreement (Fig. 10). According to the linear free energy correlation this would indicate that the same phenomenon is underlying the changes in both values. This correlation therefore provides a clear link between $\Delta \mathrm{p} K_{\mathrm{a}}$ and the electronic properties of the esters.

In addition, highly similar $\Delta \mathrm{p} K_{\mathrm{a}}$ values found for $N$-acetylated canonical amino acids (Gly and Ala) and their $N$-methylated analogues (Sar and MeAla) support the conclusion that $\Delta \Delta G$ originates from the geometric alignment of the carbonyl groups. Thus the $\Delta \Delta G$ values can equally well characterize the peptide bond alignment energy as the values of $\Delta G_{\text {trans/cis }}$ for the structurally similar proline analogues. However, the subtraction of the steric effects in $\Delta \Delta G$ values allows for the comparison of a large variety of amino acids, and is not necessarily restricted to structurally similar systems.

\subsection{Effects of the charged carboxylate}

It has also been previously reported that the Ac-Pro- $\mathrm{O}^{-}$salt exhibits the dominance of the s-cis rotameric form, that was interpreted as the repulsion between the two polar groups, when the terminal carboxyl is charged (Scheme 3A). ${ }^{32,33}$ Another hypothetical explanation for the s-cis dominance in the salt 
A<smiles>CC(=O)N1CCCC1C(=O)O</smiles>

s-trans

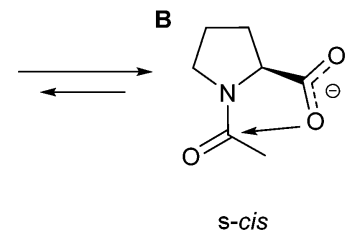

Scheme 3 Alternative explanations for the dominance of the s-cis-Ac-ProO- rotamer in the salt form: (A) destabilization of s-trans-Ac-Pro- $\mathrm{O}^{-}$due to the repulsion of the polar groups; (B) stabilization of s-cis-Ac-Pro- $\mathrm{O}^{-}$due to backward $n \rightarrow \pi^{\star}$ donation.

would be an establishment of a backward $n \rightarrow \pi^{*}$ donation from the nucleophilic carboxylate to the carbonyl group of the amide (Scheme $3 \mathrm{~B}) .{ }^{34}$ In this case, when such interactions are present, they will also contribute to the $\Delta \Delta G$ values.

In order to test the presence of the carboxylate effects we first studied the dependence of the amide rotational barriers upon the charge separation strength of the solvent $\left(E_{\mathrm{T}}\right.$ values $){ }^{35,36}$ For the ester form, both activation barriers exhibited the same slope (Fig. 11A) due to the solvent effect on the amide ground state (Scheme 4), irrespective of the s-trans and s-cis rotameric forms. ${ }^{37}$

In the case of the salt Ac-Pro- $\mathrm{O}^{-}$the interaction between the charged carboxylate and the solvent can attenuate the carboxylate interactions shown in Scheme 3. When comparing the salt to the ester, the slopes in the $E_{\mathrm{T}}-E_{\mathrm{a}}$ coordinates will change: (1) for trans-cis towards an increase in the case of the carboxylatecarbonyl repulsion (Scheme 3A) which is a destabilizing effect, and (2) for cis-trans towards a decrease in the case of the backward $n \rightarrow \pi^{*}$ donation (Scheme 3B) which is a stabilizing effect. Our experimental observations presented in Fig. 11B revealed that the first scenario appeared to be valid, whereas there was no support for the hypothesis that the backward $n \rightarrow \pi^{*}$ donation was occurring.

As one possible interpretation, the equilibrium was strongly shifted towards the s-cis rotamer in the solvents with a low acceptor number (Fig. 11C). ${ }^{38}$ Thus, highly polar solvents reduce the carboxylate-carbonyl repulsion. In the terminal case, water seems to quench the repulsion, leading to nearly equilibrated s-trans and s-cis populations. This is supported by

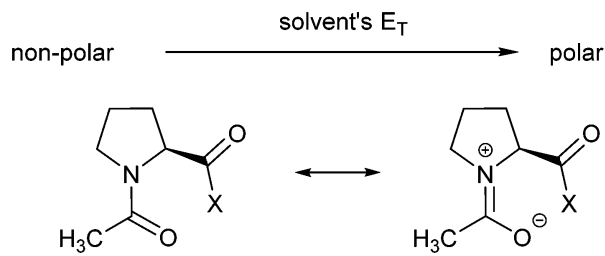

Scheme 4 Rotational barrier increases in more polar solvents with a higher ability to separate charges due to a shift of the contributions of their mesomeric structures in the ground states. ${ }^{35}$<smiles>CC(=O)N1CCCC1[O+]</smiles><smiles>CC(=O)N1CCCC1CC(=O)[O-]</smiles><smiles>CC(=O)N1CCCC1C</smiles>

$\Delta \mathrm{H}_{\text {trans } / \text { is }} / \mathrm{kJ} / \mathrm{mol}=$ $-1.17 \pm 0.10$ $-0.90 \pm 0.09$

$-1.11 \pm 0.06$

$\mathrm{K}_{\text {trans/cis }}=$

$$
0.81 \pm 0.02
$$

$1.11 \pm 0.01$

$1.27 \pm 0.02$

Fig. 12 Enthalpic terms of the trans/cis equilibrium determined for the salt of $N$-acetyl proline (1), $N$-acetyl- $\beta$-homoproline (20) and in $N$-acetyl2-methylpyrrolidine (21) reveal their close similarity.

the observation that the salt trans/cis ratios found in water $(0.81)$ and the water-acetonitrile mixture $(0.79)$ are indistinguishable from the value in trifluoroethanol (0.79) (for comparison of the full solvent set see Fig. S68, ESI†).

The absence of the carboxylate effects is further supported by the finding that $\Delta H_{\text {trans/cis }}$ values are nearly identical in substrates similar to Ac-Pro-O ${ }^{-}$(Fig. 12). Therefore, it seems to be evident that the $\Delta \Delta G$ values allow the quantification of the carbonyl alignment in the esters and acids, whereas the carboxylate effects are opposed by strong water solvation.

\section{5. $\Delta \mathrm{p} K_{\mathrm{a}}$ in non- $\alpha$-amino acids}

While in the frame of $N$-acetyl $\alpha$-amino acids, the $\Delta \mathrm{p} K_{\mathrm{a}}$ values were found to vary in the range of $0.4-0.8$ units, an increase of the chain length between the functionalities should lead to an attenuation of the interaction between the carbonyl groups.
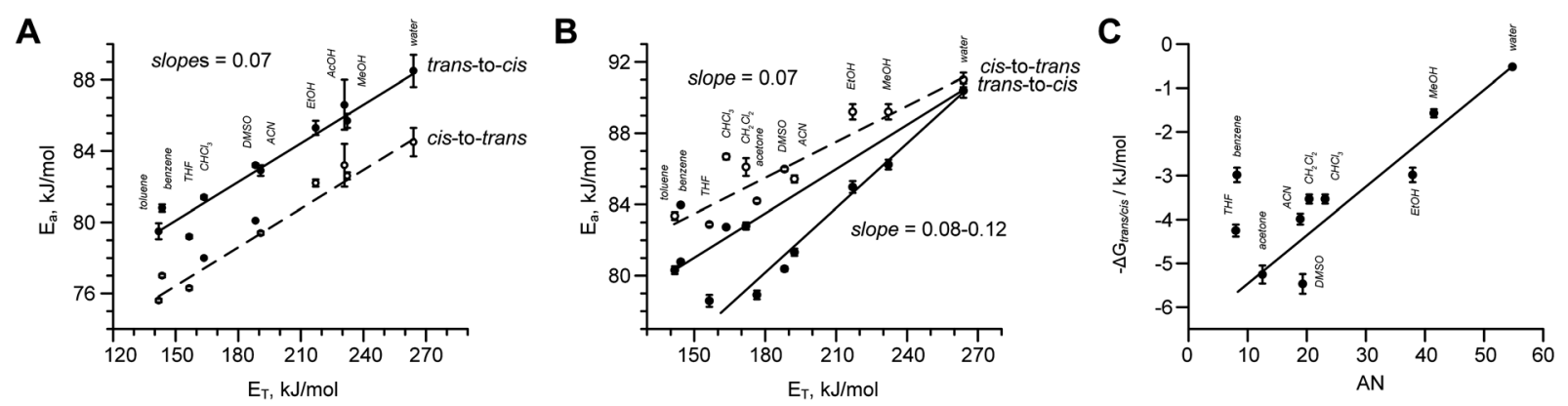

Fig. 11 Correlations between the amide rotational barriers and Reichardt-Dimroth solvent parameter (defined as the ability of the solvent to separate charges): (A) for $60 \mathrm{mM} \mathrm{Ac-Pro-OMe} \mathrm{at} 298 \mathrm{~K}$; (B) for the $20 \mathrm{mM} \mathrm{Ac-Pro-OK-18-crown-6} \mathrm{complex} \mathrm{at} 310 \mathrm{~K}$ (in dichloromethane at $298 \mathrm{~K}$, in water at $340 \mathrm{~K})$. Straight line, solid circles - activation barriers for the trans-to-cis isomerization; dashed line, opened circles - for the cis-to-trans isomerization. (C) Correlation of the equilibrium free energy differences in $\mathrm{Ac}^{-P r o-} \mathrm{O}^{-}$and the solvent acceptor number. 
Table 3 Rotameric acidity differences in the amino acids with increasing chain length

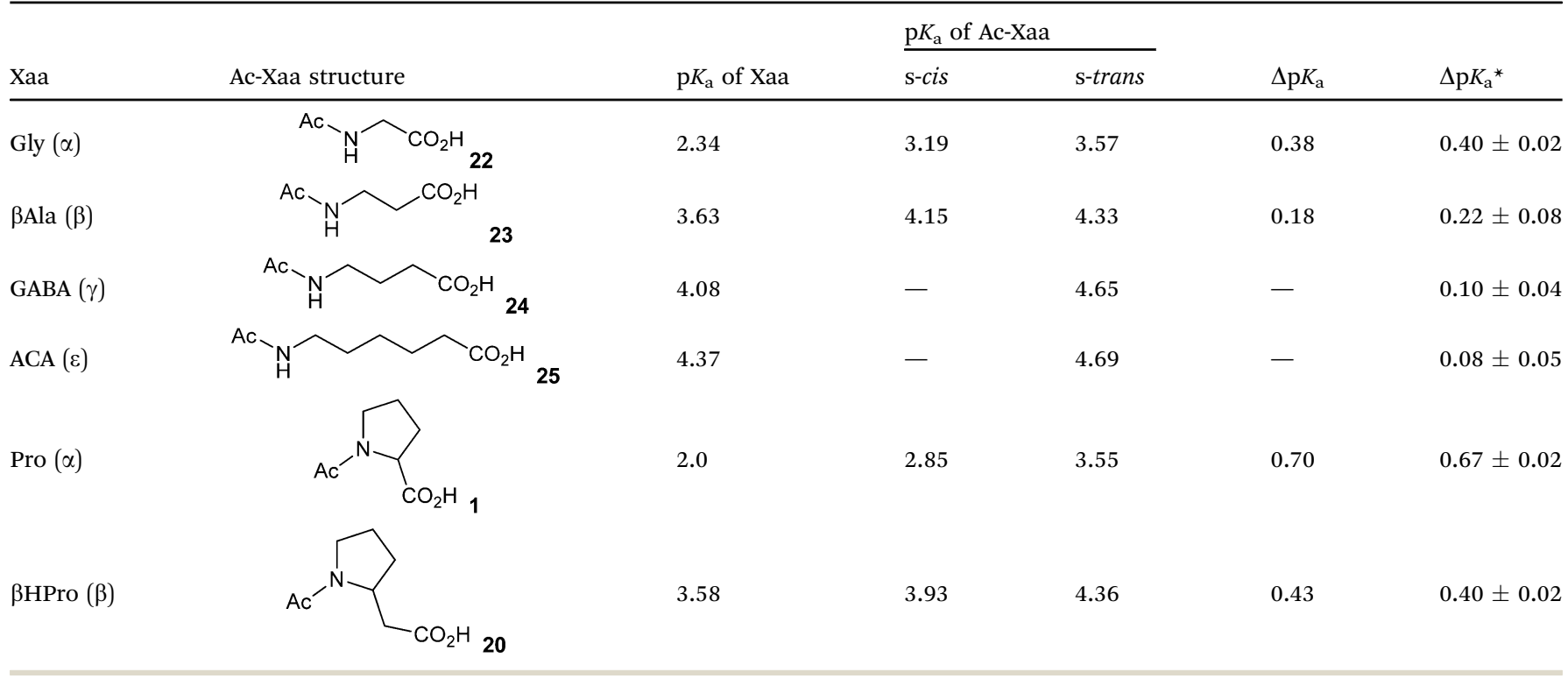

Due to the specific nature of the $n \rightarrow \pi^{*}$ interaction, we would not expect it to occur with increasing chain length, with this effect already being drastically diminished in the frame of an $N$-acetyl $\beta$-amino acid. The dipole-dipole interaction should also vary dramatically in the homologous $N$-acetyl amino acids, decreasing a stabilizing interaction with increasing chain length. The question, what should be the case was addressed through experiment.

Experimentally we found in the case of Ac- $\beta$ Ala both $\Delta \mathrm{p} K_{\mathrm{a}}$ and $\Delta \mathrm{p} K_{\mathrm{a}}{ }^{*}$ to be approximately 0.2 , which is about a half of the values of Ac-Gly. Next, for Ac-GABA the $\Delta \mathrm{p} K_{\mathrm{a}}{ }^{*}$ was about 0.1 (Table 3). We observed an exponential decrease of the effect by a factor of 2 for each subsequent $\mathrm{CH}_{2}$ unit. It is further seen from Fig. 13 that the effect originates in the uncharged compounds: acids and esters. Only in these species did we expect a significant $\mathrm{C}=\mathrm{O}$ dipole (Fig. 6). Then the alignment of this

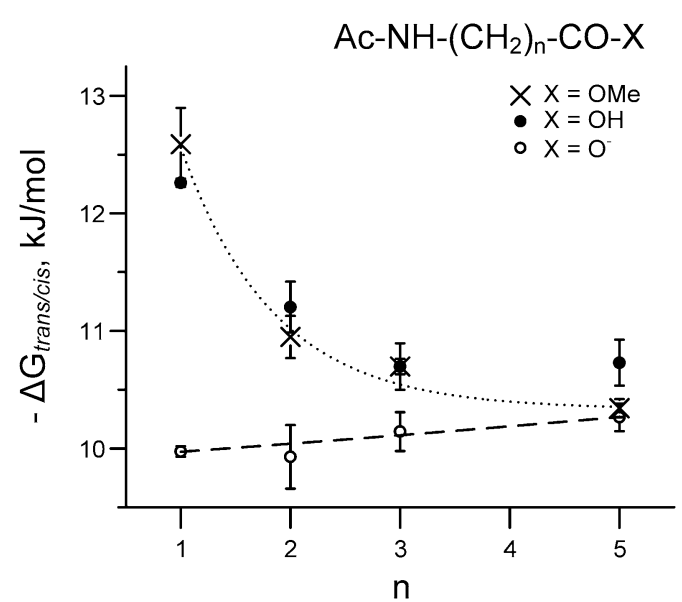

Fig. 13 Energy difference between s-trans and s-cis rotational states in unsubstituted $\mathrm{N}$-acetyl amino acids. The attractive effect exponentially decays with increasing chain length.

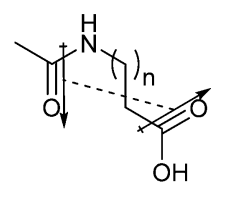

s-trans

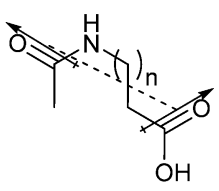

s-cis
Fig. 14 The distance between two interacting dipoles should be closer in the s-trans conformation of an $\mathrm{N}$-acetyl amino acid.

dipole with that of the amide is stronger in the case of the s-trans conformation, arising from their closer proximity, as illustrated in Fig. 14.

For Ac-Pro and Ac- $\beta$ HPro, the $\Delta \mathrm{p} K_{\mathrm{a}}$ values were generally higher, 0.7 and 0.4 units respectively. The higher $\Delta \mathrm{p} K_{\mathrm{a}}$ for cyclic systems can arise from the reduced degree of conformational freedom present in the ring forms. A cyclic residue necessarily has fewer conformations that it can adopt, leading to a preorganization effect, hence leading to a greater impact on $\Delta \mathrm{p} K_{\mathrm{a}}$ when compared to the acyclic systems.

\subsection{Accumulation of the effect on $\Delta \mathrm{p} K_{\mathrm{a}}$ in a growing peptide chain}

Overall the origin of the $\Delta \mathrm{p} K_{\mathrm{a}}(\Delta \Delta G$ energetic term) can be seen as donation (of $n \rightarrow \pi^{*}$ and/or dipole-dipole origin) that only occurs in the s-trans rotamer. Such treatment predicts that the donation effect could accumulate in the all-trans peptide chain. In particular, it could provide a motif for PPII folding cooperativity. For this reason we studied both the acidity and the population differences in the Ac-Pro-Pro dipeptide. This dipeptide contains four rotameric forms (Fig. 15), and the acidity difference between trans-trans and cis-trans rotamers would indicate a cascade accumulation of the donative effect (Fig. 16).

It is well known that Pro-Pro connectivity exhibits the smallest s-cis content among all Xaa-Pro fragments (where Xaa is a 


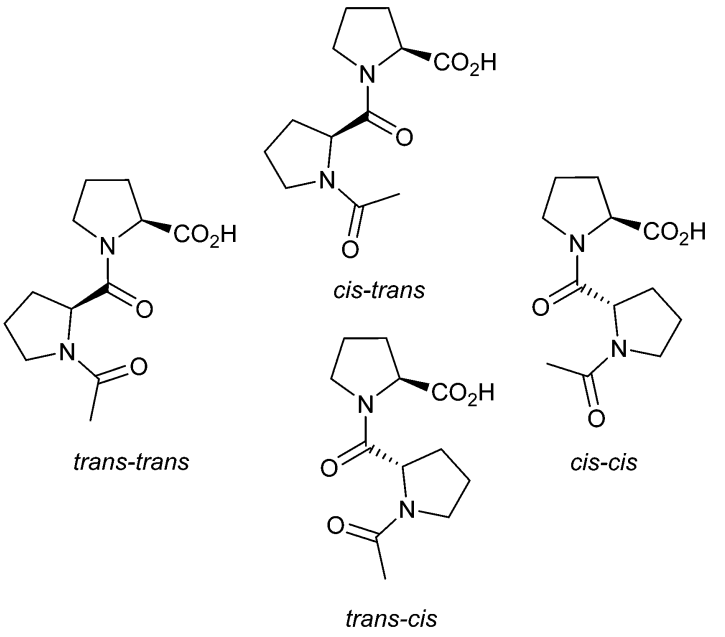

Fig. 15 Rotameric forms of Ac-Pro-Pro.

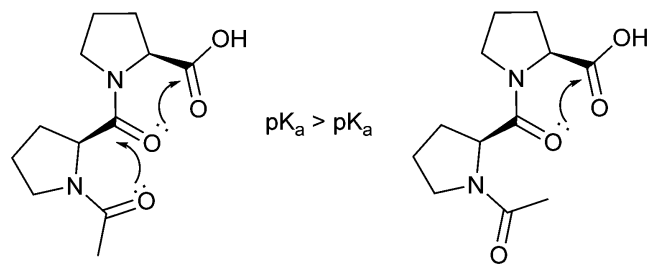

Fig. 16 Cascade donation in the chain of s-trans amide bonds in Ac-Pro-Pro.

Table 4 Thermodynamic populations ${ }^{a}$ and acidities of Ac-Pro-Pro rotameric forms

\begin{tabular}{llllc}
\hline & $\begin{array}{l}\text { trans-trans } \\
\mathrm{p} K_{\mathrm{a}}\end{array}$ & $\begin{array}{l}\text { cis-trans } \\
3.59\end{array}$ & $\begin{array}{l}\text { trans-cis } \\
3.19\end{array}$ & $\begin{array}{l}\text { cis-cis } \\
2.66\end{array}$ \\
Populations, \% & Pro-Pro in s-trans & \multicolumn{2}{c}{ Pro-Pro in s-cis } \\
\hline Acid (pH 1.4) & 75 & 18 & & 7 \\
& $(75)$ & $(18)$ & $(4)$ & $(3)$ \\
Salt (pH 7.1) & 58 & 18 & 7 & 17 \\
& $(58)$ & $(17)$ & $(7)$ & $(18)$ \\
Methyl ester & 75 & 18 & 4 & 3
\end{tabular}

${ }^{a}$ Determined by ${ }^{1} \mathrm{H}$ NMR (error $\pm 1 \%$ ), in parentheses $-{ }^{13} \mathrm{C}$ NMR intensities (error $\pm 1.5 \%$ ).

canonical residue). ${ }^{39}$ We also found the domination of the s-trans Pro-Pro connection in Ac-Pro-Pro which was 93\% in the acidic and $76 \%$ in the salt forms respectively (Table 4). The overall change upon salt-base transition corresponds to the free energy difference $\Delta \Delta G=-R T \ln ((93 / 7) /(76 / 24))=-3.6 \mathrm{~kJ} \mathrm{~mol}^{-1}$ (or $\Delta \mathrm{p} K_{\mathrm{a}}{ }^{*}=0.62$ ), slightly lower than that has been observed for Ac-Pro $\left(\Delta \mathrm{p} K_{\mathrm{a}}{ }^{*}=0.67\right)$. For the case of the s-trans Pro-Pro amide bond rotameric state of the upstream $\mathrm{N}$-acetyl moiety exhibited a further impact on the C-terminal acidity. The transtrans form was found to be less acidic than cis-trans by $0.08 \mathrm{p} K_{\mathrm{a}}$ units, or 0.11 when calculated from the equilibrium populations (as $\left.\log _{10}((75 / 18) /(58 / 18))\right)$. This is a small, but detectable difference which makes about $1 / 6$ of the overall $\Delta \mathrm{p} K_{\mathrm{a}}{ }^{*}$.

We suggest therefore that the cooperativity of the PPII folding is thermodynamically supported by the energy enhancement arising in a cascade fashion, which can be treated as a donation. This consideration can be illustrated in the following way. In a polyproline chain the probability for the amide bond to form a trans-amide bond is $93 \%$. This value is defined by the $\Delta G_{\text {trans/cis }}$ of the Pro-Pro connectivity. Statistically, this would mean that for each 14 residues in polyproline, one will have a cis-conformation. Taking that the cooperativity provides $1 / 6$ of one peptide bond alignment energy $\left(\sim 0.6 \mathrm{~kJ} \mathrm{~mol}^{-1}\right)$, this will immediately decrease the rate of cis-bond appearance to one in 18 residues. Further growth of the polypeptide chain may create additional factors that would enforce stronger alignment.

Noteworthily, we also found the dominance of cis-cis form over trans-cis in the salt form of Ac-Pro-Pro. This cooperative effect results in the nucleation of the PPI helix (all amide bonds in s-cis conformation) ${ }^{32}$ already in a context of two residues. Comparison of the acidity values of the cis-trans (3.19) and cis-cis (2.66) forms of Ac-Pro-Pro with the acidity of s-cis-Ac-Pro (2.85) indicates that this is the effect of destabilization of trans-cisAc-ProPro-O $^{-}$, rather than the stabilization of cis-cis-Ac-ProPro-O $^{-}$. We hypothesize that this destabilization could occur in particular due to the close proximity of the $\mathrm{N}$-terminal carbonyl oxygen to the C-terminal carboxyl-group in the trans-cis conformation. However, we did not study this phenomenon in further detail.

Finally, similar acidity values found for s-trans Ac-Pro (3.55) and trans-trans-Ac-Pro-Pro (3.59) suppose similar chemical reactivity of the C-terminal carbonyl group towards nucleophilic reactions. Thus, the oligoproline stalling cannot originate from the donative effects of the carbonyl alignment. This conclusion is supported by our recent kinetic observations of the ribosomal translation rates, which indicate only a minor effect of the C-terminal acidity variation on the translational velocity of proline and its analogues. ${ }^{40}$

\section{Conclusions}

The presented experimental results confirmed that the acidity of $\mathrm{N}$-acetylated amino acids is lower when the amide bond is $\mathrm{s}$-trans $\left(\Delta \mathrm{p} K_{\mathrm{a}}>0\right)$ in a general case. Similarly, s-trans rotameric populations were always higher for the case of protonated carboxylates $\left(\Delta \mathrm{p} K_{\mathrm{a}}{ }^{*}>0\right)$. This phenomenon evidently arises from the mutual interaction of the carbonyl groups in the context of amino acids. Therefore, $\Delta \mathrm{p} K_{\mathrm{a}}$, or $\Delta \mathrm{p} K_{\mathrm{a}}{ }^{*}$ reflects the magnitude of the peptide bond alignment stabilization energy as evident from the comparison of the homologous $N$-acetyl $\alpha$-, $\beta$-, $\gamma$ - and $\varepsilon$-amino acids. In addition, the energy of this interaction in Ac-Pro-NHMe as compared to Ac-Pro-O ${ }^{-}$provides $\Delta \Delta G=-3.3 \mathrm{~kJ} \mathrm{~mol}^{-1}\left(\Delta \Delta H=-2.8 \mathrm{~kJ} \mathrm{~mol}^{-1}\right)$. This amount accounts for about $1 / 2$ of one hydrogen bond energy in a $\beta$-sheet. ${ }^{41} \mathrm{~A}$ similar value of $-2.7 \mathrm{~kJ} \mathrm{~mol}^{-1}$ was previously provided by Hinderaker and Raines. ${ }^{42}$

\section{Outlook}

Considerations of the peptide bond alignment energy may also have biological significance, especially in understanding the 
evolution of the genetic code, which defines the evolutionary appearance of the amino acids in translated proteins. Proline is considered to be one of the first amino acids recruited to translation upon transition of the RNA to protein World. ${ }^{43,44}$ However, other secondary amino acids are widely abundant in living organisms. For instance, Sar is massively generated by enzymatic methyl-transfer from $S$-adenosyl-methionine for the regulation of the cellular $\mathrm{C}_{1}$-pool. ${ }^{45}$ Pipecolic acid, a metabolic product of lysine, is produced in a similar fashion to proline. ${ }^{46}$ Aze is a toxic proline substitute which is produced in some plants as a defence mechanism. ${ }^{47}$ Despite their widespread metabolic abundance and the fact that they are also found in meteorites, ${ }^{48,49}$ Sar and Pip are paradoxically not involved in ribosomal translation. However, nature only recruited proline to the genetic code as the sole secondary amino acid. Among the others, one possible reason for this choice could be the stabilization of the ordered structures with motifs resistant to changing conditions: $\mathrm{pH}$, salt concentrations, etc. In other words, the high energy of the peptide bond alignment provided by the proline's structure (and may be, $\alpha$-amino acids in general) might be one of the rationales behind the choice of this amino acid as the basic structural building block for proteins. ${ }^{50}$

\section{Acknowledgements}

This project was granted in the frame of the DFG research group 1805 "Ribosome Dynamics in Regulation of Speed and Accuracy of Translation". The work of P. D. was supported by UniCat cluster TU Berlin. Prof. Igor Komarov (Kyiv, Ukraine) is acknowledged for discussions. We also thank Dr Pavel K. Mykhailiuk (Kyiv) for the provision of a Pdc derivative and discussion.

\section{References}

1 J. Kurtz, A. Berger and E. Katchalski, Nature, 1956, 178, 1066-1067.

2 W. A. Elam, T. P. Schrank, A. J. Campagnolo and V. J. Hilser, Protein Sci., 2013, 22, 405-417.

3 A. A. Adzhubei, M. J. E. Sternberg and A. A. Makarov, J. Mol. Biol., 2013, 425, 2100-2132.

4 It has been described as a preffered conformation in particular: (a) polyglutamate, M. L. Tiffany and S. Krimm, Biopolymers, 1968, 6, 1379-1382; (b) for polyalanine, M. Mezei, P. J. Fleming, R. Srinivasan and G. D. Rose, Proteins, 2004, 55, 502-507; (c) polylysine, A. L. Rucker and T. P. Creamer, Protein Sci., 2002, 11, 980-985.

5 Though, reported in some relevant examples, for instance: D. Cardinale, G. Guaitoli, D. Tondi, R. Luciani, S. Henrich, O. M. H. Salo-Ahen, S. Ferrari, G. Marverti, D. Guerrieri, A. Ligabue, C. Frassineti, C. Pozzi, S. Mangani, D. Fessas, R. Guerrini, G. Ponterini, R. C. Wade and M. P. Costi, Proc. Natl. Acad. Sci. U. S. A., 2011, 108, E542-E549.

6 M. M. Harding, P. I. Anderberg and A. D. J. Haymet, Eur. J. Biochem., 2003, 270, 1381-1392.
7 A. A. Adzhubei and M. J. E. Sternberg, J. Mol. Biol., 1993, 229, 472-493.

8 N. W. Owens, C. Braun, J. D. O'Neil, K. Marat and F. Schweizer, J. Am. Chem. Soc., 2007, 129, 11670-11671.

9 G. J. Bartlett, A. Choudhary, R. T. Raines and D. N. Woolfson, Nat. Chem. Biol., 2010, 6, 615-620.

10 (a) J. A. Hodges and R. T. Raines, Org. Lett., 2006, 8, 4695-4697; (b) A. Choudhary, C. G. Fry, K. J. Kamer and R. T. Raines, Chem. Commun., 2013, 49, 8166-8168.

11 A. Choudhary, R. W. Newberry and R. T. Raines, Org. Lett., 2014, 16, 3421-3423.

12 (a) B. Worley, G. Richard, G. S. Harbison and R. Powers, PLoS One, 2012, 7, e42075; (b) K. J. Kamer, A. Choudhary and R. T. Raines, J. Org. Chem., 2013, 78, 2099-2103.

13 P. Wilhelm, B. Lewandowski, N. Trapp and H. Wennemers, J. Am. Chem. Soc., 2014, 136, 15829-15832.

14 M. D. Shoulders, K. A. Satyshur, K. T. Forest and R. T. Raines, Proc. Natl. Acad. Sci. U. S. A., 2010, 107, 559-564.

15 M. D. Shoulders and R. T. Raines, Annu. Rev. Biochem., 2009, 78, 929-958 and references therein.

16 (a) S. Ude, J. Lassak, A. L. Starosta, T. Kraxenberger, D. N. Wilson and K. Jung, Science, 2013, 339, 82-85; (b) L. K. Doerfel, I. Wohlgemuth, C. Kothe, F. Peske, H. Ulraub and M. V. Rodnina, Science, 2013, 339, 85-88.

17 (a) L. Peil, A. L. Starosta, J. Lassak, G. C. Atkinson, K. Virumäe, M. Spitzer, T. Tenson, K. Jung, J. Remme and D. N. Wilson, Proc. Natl. Acad. Sci. U. S. A., 2013, 110, 15265-15270; (b) A. L. Starosta, J. Lassak, L. Peil, G. C. Atkinson, K. Virumäe, T. Tenson, J. Remme, K. Jung and D. N. Wilson, Nucleic Acids Res., 2014, 42, 10711-10719.

18 M. Larregola, S. Moore and N. Budisa, Biochem. Biophys. Res. Commun., 2012, 421, 646-650.

19 Previously reported values for Ac-Pro: $\mathrm{p} K_{\mathrm{a}}^{\mathrm{D}}$ s-trans $4.13 \pm$ 0.08 and s-cis $3.47 \pm 0.08, \Delta \mathrm{p} K_{\mathrm{a}}^{\mathrm{D}}=0.66 \pm 0.08$ at $303 \mathrm{~K}$ in (a) G. R. Bedford and P. J. Sadler, Biochim. Biophys. Acta, 1974, 343, 656-662; and $\mathrm{p} K_{\mathrm{a}} \mathrm{s}$-trans $3.36 \pm 0.02$, s-cis $2.79 \pm$ $0.02, \Delta \mathrm{p} K_{\mathrm{a}}=0.57 \pm 0.02$ at $313 \mathrm{~K}$ in ; (b) R. N. Hunston, I. P. Gerothanassis and J. Lauterwein, J. Am. Chem. Soc., 1985, 107, 2654-2661.

20 C. A. Evans and D. L. Rabenstein, J. Am. Chem. Soc., 1974, 96, 7312-7317.

21 Bulk water suppression become available only in 1990s with the advent of the pulsed field gradient technique, see: T. Parella, Magn. Reson. Chem., 1998, 36, 467-495.

$22 \mathrm{p} K_{\mathrm{a}}$ determination using heteronuclear experiments with proton decoupling is risky, due to the differences in both magnetization recycling and NOE enhancement that may occur in the two ionized states and that might produce a distorted average of the chemical shifts.

23 F. Blomberg, H. Rüterjans, K. Lintner, F. Toma and S. Fermandjian, Org. Magn. Reson., 1978, 11, 598-602.

24 For instance, the $n \rightarrow \pi^{*}$ interaction contributes to the acidity of aspirin: A. Choudhary, K. J. Kamer and R. T. Raines, J. Org. Chem., 2011, 76, 7933-7937.

25 (a) A. L. Van Geet, Anal. Chem., 1970, 42, 679-680; (b) D. S. Raiford, C. L. Fisk and E. D. Becker, Anal. Chem., 
1979, 51, 2050-2051; (c) C. Ammann, P. Meier and A. E. Merbach, J. Magn. Reson., 1982, 46, 319-321.

26 C. M. Taylor, R. Hardré, P. J. B. Edwards and J. H. Park, Org. Lett., 2003, 5, 4413-4416.

27 C. Renner, S. Alefelder, J. H. Bae, N. Budisa, R. Huber and L. Moroder, Angew. Chem., Int. Ed., 2001, 40, 923-925.

$28 \Delta \mathrm{p} K_{\mathrm{a}}{ }^{*}$ of Ac-Pip calculated from the previously reported values is in good agreement: 0.25 . Whereas for Ac-Aze the salt rotamers have been wrongly assigned: R. E. Galardy, J. R. Alger and M. Liakopoulou-Kyriakides, Int. J. Pept. Protein Res., 1982, 19, 123-132.

29 (a) V. Kubyshkin, S. Afonin, S. Kara, N. Budisa, P. K. Mykhailiuk and A. S. Ulrich, Org. Biomol. Chem., 2015, 13, 3171-3181; (b) V. Kubyshkin and N. Budisa, Beilstein J. Org. Chem., 2016, 12, 589-593.

30 A. Lesarri, E. J. Cocinero, J. C. López and J. L. Alonso, J. Am. Chem. Soc., 2005, 127, 2572-2579.

31 As supporting this conclusion see also: C. M. Taylor, R. Hardré and P. J. B. Edwards, J. Org. Chem., 2005, 70, 1306-1315.

32 M. Kuemin, S. Schweizer, C. Ochsenfeld and H. Wennemers, J. Am. Chem. Soc., 2009, 131, 15474-15482.

33 Similarly we recently observed in aminoisoxazoles: B. A. Chalyk, I. Y. Kandaurova, K. V. Hrebeniuk, O. V. Manoilenko, I. B. Kulik, R. T. Iminov, V. Kubyshkin, A. V. Tverdokhlebov, O. K. Ablialimov and P. K. Mykhailiuk, $R S C A d v$., 2016, 6, 25713-25723.

34 In particular, this effect has been demonstrated along with $n)(\pi$ repulsion, when proline carboxylate was exchanged to either oxazine or thiazine moieties: D. N. Reddy, R. Thirupathi, S. Tumminakatti and E. N. Prabhakaran, Tetrahedron Lett., 2012, 53, 4413-4417.

35 E. S. Eberhardt, S. N. Loh, A. P. Hinck and R. T. Raines, J. Am. Chem. Soc., 1992, 114, 5437-5439.
36 K. B. Wiberg, P. R. Rablen, D. J. Rush and T. A. Keith, J. Am. Chem. Soc., 1995, 117, 4261-4270.

37 It has also been reported previously that the solvent effect only has a minor influence on the trans/cis ratio: C. B. Braga, L. C. Ducati, C. F. Tormena and R. Rittner, J. Phys. Chem. A, 2014, 118, 1748-1758.

38 V. Gutmann, Electrochim. Acta, 1976, 21, 661-670.

39 G. Fischer, Chem. Soc. Rev., 2000, 29, 119-127.

40 L. K. Doerfel, I. Wohlgemuth, V. Kubyshkin, A. L. Starosta, D. N. Wilson, N. Budisa and M. V. Rodnina, J. Am. Chem. Soc., 2015, 137, 12997-13006.

41 S.-Y. Sheu, D.-Y. Yang, H. L. Selzle and E. W. Schlag, Proc. Natl. Acad. Sci. U. S. A., 2003, 100, 12683-12687.

42 M. P. Hinderaker and R. T. Raines, Protein Sci., 2003, 12, 1188-1194.

43 J. T.-F. Wong, Proc. Natl. Acad. Sci. U. S. A., 1975, 72, 1909-1912. 44 H. Hartman and T. F. Smith, Life, 2014, 4, 227-249.

45 (a) M. H. Stipanuk, Annu. Rev. Nutr., 1986, 6, 179-209; (b) A. D. Hanson and S. Roje, Annu. Rev. Plant Phisiol. Plant Mol. Biol., 2001, 52, 119-137.

46 (a) Y.-F. Chang, Biochem. Biophys. Res. Commun., 1976, 69, 174-180; (b) H. P. Broquist, Annu. Rev. Nutr., 1991, 11, 435-448.

47 (a) L. Fowden, Biochem. J., 1956, 64, 323-332; (b) E. Rubenstein, T. McLaughlin, R. C. Winant, A. Sanchez, M. Eckart, K. M. Krasinska and A. Chien, Phytochemistry, 2009, 70, 100-104.

48 K. A. Kvenvolden, J. G. Lawless and C. Ponnamperuma, Proc. Natl. Acad. Sci. U. S. A., 1971, 68, 486-490.

49 J. R. Cronin and S. Pizzarello, Adv. Space Res., 1983, 3, 5-18. 50 For interesting discussions regarding the special role of proline see: (a) B. K. Kay, M. P. Williamson and M. Sudol, FASEB J., 2000, 14, 231-241; (b) A. C. Forster, Biotechnol. J., 2012, 7, 835-845. 